\title{
Development and validation of first and zero order derivative spectrophotometric methods for the determination of rilmenidine in pharmaceutical preparations and forced degradation study
}

\author{
Ayça KARASAKAL 1 * (D), Elif ÖZDEMİR 2 (D)

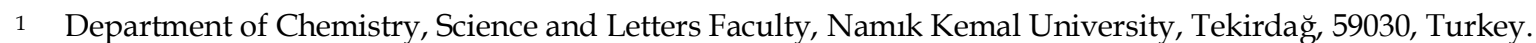 \\ 2 Department of Analytical Chemistry, Pharmacy Faculty, İstanbul Yeni Yüzyıl University, İstanbul, 34010, Turkey. \\ * Corresponding Author. E-mail: akarasakal@nku.edu.tr (A.K.); Tel. +90-282-250 2658.
}

Received: 05 January 2019 / Revised: 11 February 2019 / Accepted: 05 March 2019

\begin{abstract}
Zero and first order derivative spectrophotometric methods were developed for the analysis of rilmenidine in pharmaceutical preparations. Absorbances of rilmenidine were measured at $224 \mathrm{~nm}$ for the zero order by measuring height of peak from zero and at 223.20 and $230.20 \mathrm{~nm}$ for the first order derivative spectrophotometric method by measuring peak to peak height. The linearity ranges were found to be $50-250 \mu \mathrm{g} / \mathrm{mL}$ for zero and first order spectrophotometric method. The developed methods were validated and the analytical parameters of linearity, limit of detection, limit of quantification, accuracy, precision and recovery were evaluated. In addition, Rilmenidine exposed to the stress conditions of acid, base and oxidative in order to calculate to degradation \% by developed zero and first order derivative spectrophotometric method.
\end{abstract}

KEYWORDS: Rilmenidine; derivative spectrophotometric method; forced degradation study; validation.

\section{INTRODUCTION}

Currently, the high worldwide prevalence of hypertension in adults is a major public health problem Hypertension has become a leading cause of cardiovascular disease, which accounts for a high proportion of premature mortality and contributes to 7 million deaths each year. [1-7] Today, there are various drug treatment classifications used in the treatment of hypertension, commonly referred to as antihypertensive drugs. [8-11] Antihypertensive drugs were categorized into six separate drug groups: Angiotensin converting enzyme (ACE)-inhibitors, Angiotensin-receptor blockers (ATR-blockers), diuretics, beta-blockers, calciumchannel blockers and other antihypertensive drugs. [12] Rilmenidine is an antihypertensive agent with selectivity for I1 imidazoline receptors that acts both centrally by reducing sympathetic overactivity and in the kidney by inhibiting the $\mathrm{Na}^{+} / \mathrm{H}^{+}$antiport. Rilmenidine provides antihypertensive efficacy comparable with that of diuretics, beta-blockers, calcium channel blockers, and angiotensin-converting enzyme (ACE) inhibitors. [13] Rilmenidine phosphate (RIL)'s chemical formula is RN-(dicyclopropylmethyl)-4,5-dihydro-1,3oxazol-2-amine phosphoric acid. [14] Rilmenidine is not subjected to pre-systemic metabolism and is rapidly and extensively absorbed with time to peak plasma concentrations between 1.5 to $2 \mathrm{~h}$. [15-16] It isn't reported in literature determination of RIL by zero and first order derivative spectrophotometric methods but there is only one method described for quantification of rilmenidine by LC-MS/MS in human serum. [17] The derivative spectrophotometric method is one of the advanced modern spectrophotometric techniques that supply a functional means for extracting both qualitative and quantitative information from the spectra composed of overlapped bands. It is based on using the first- or higher-order derivatives of absorbance with respect to wavelength from parent zero-order ones. Because derivatization can lead to the separation of unresolved signals and reduction of spectral background interferences, this technique permits the quantification of one analyte in the presence of others without initial separation or purification. [18] The derivative spectrophotometry consists of calculating and plotting one of the mathematical derivatives of a spectral curve. [19] There are several studies based on derivatization in the literature for analysis of drug substances. [19,21-25] Force degradation studies were performed on the placebo and drug products to show the stability-indicating nature of the method. These studies were performed in accordance with established

How to cite this article: Karasakal A, Özdemir E. Development and validation of first and zero order derivative spectrophotometric methods for the determination of rilmenidine in pharmaceutical preparations and forced degradation study. J Res Pharm. 2019; 23(3): 457-464. 
ICH guidelines. [26-27] In addition, the aim of this work was to develop stability methods for estimation of percentage degradation of RIL by zero and first order derivative spectrophotometric methods. The developed methods were applied to the determination of RIL in commercially available tablets and were validated for accuracy, precision, recovery, linearity and stability to forced degradation studies according to the prescribed procedures mentioned in ICH guidelines. [20]

\section{RESULTS}

Figure 1 shows Rilmenidine phosphate (RIL) chemical formula. In this study to obtain more sensitive results, the first, second, third and fourth derivative spectra of RIL was achieved and then it was determined that first derivative was the best. In addition, we compared with first and zero order derivative spectrophotometric methods. Figure 2 shows first order derivative spectrum of $200 \mu \mathrm{g} / \mathrm{mL}$ RIL. During method development, several tests were performed in order to establish the assay parameters. The effect of different extraction solvents on the absorbance of RIL was investigated using chloroform, ethyl acetate and dichloromethane It was found that dichloromethane was the best solvent for extraction since it gave the highest absorbance. Zero order derivative spectrums of RIL shows maximum absorbance at $224 \mathrm{~nm}$ (Figure 3) and Figure 4 shows calibration curve of RIL for first order derivative spectrophotometric method. The proposed methods were successfully applied to pharmaceutical preparations. The determination of RIL tablets, Hyperium ${ }^{\circledR} 1 \mathrm{mg}$ were analyzed by zero and first order derivative spectrophotometric method. From the calibration curves, concentration of drug in \% were calculated. The recovery were found to be $105.61 \%$ \pm 3.61 and $101.73 \% \pm 2.65$ for zero and first order derivative spectrophotometric method, respectively. As the values of \% RSD and RME and the percentage recovery within the limit indicated that the methods were accurate, and when we compared blank solution with RIL's absorption wavelengths in absorption spectrum, It was observed that absorption wavelengths didn't overlay. Because of this, there is no interference from the excipients.
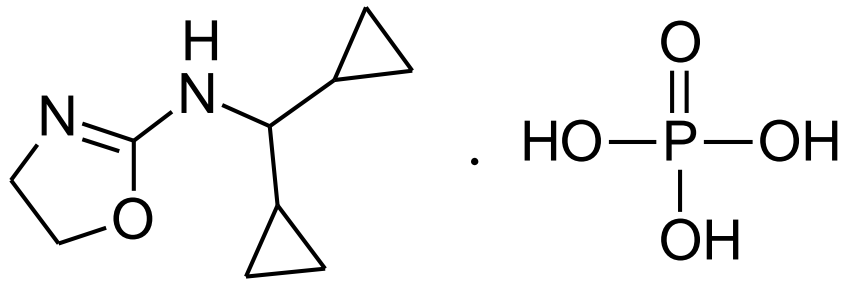

Figure 1. Chemical structure of rilmenidine phosphate (RIL).

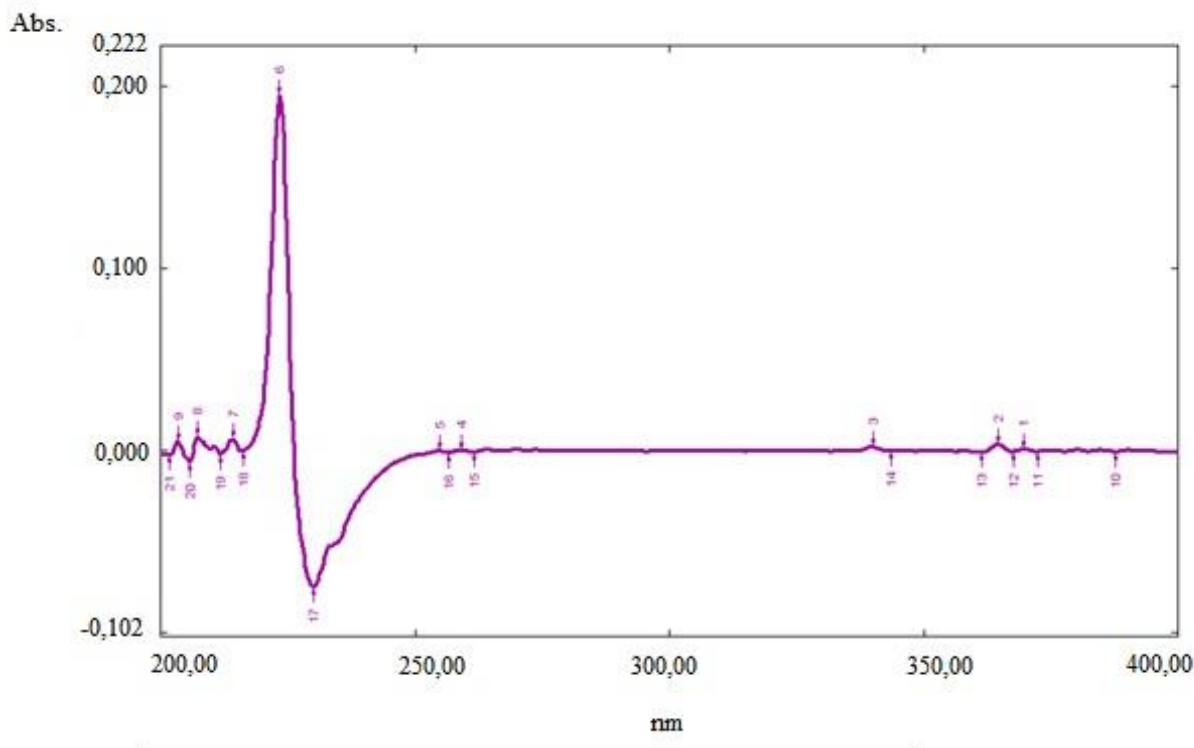

Figure 2. First order derivative spectrum of $200 \mu \mathrm{g} / \mathrm{mL}$ RIL. 


\section{DISCUSSION}

\subsection{Method validation}

\subsubsection{Linearity and Calibration Curve}

The linearity range was found to be $50-250 \mu \mathrm{g} / \mathrm{mL}$. Optical characteristics and statistical datas for zero and first order derivative spectrophotometric methods are shown in Table 1 and 2.

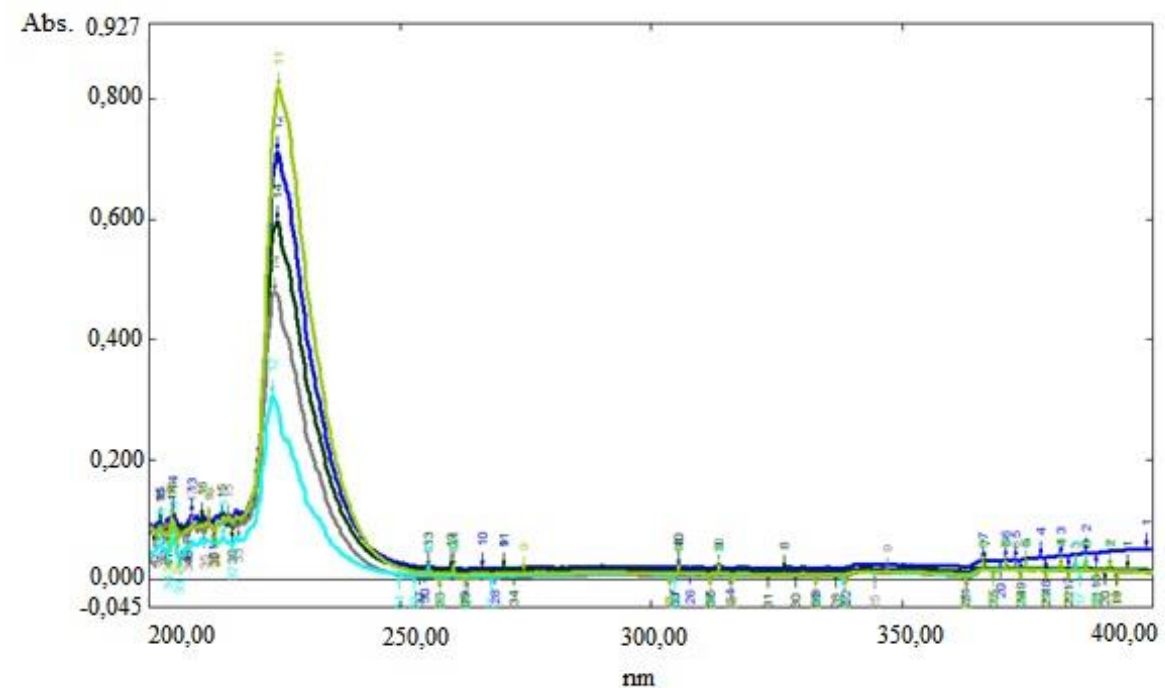

Figure 3. The absorption spectrums of RIL at various concentrations $(50-250 \mu \mathrm{g} / \mathrm{mL})$ by zero order derivative spectrophotometric method.

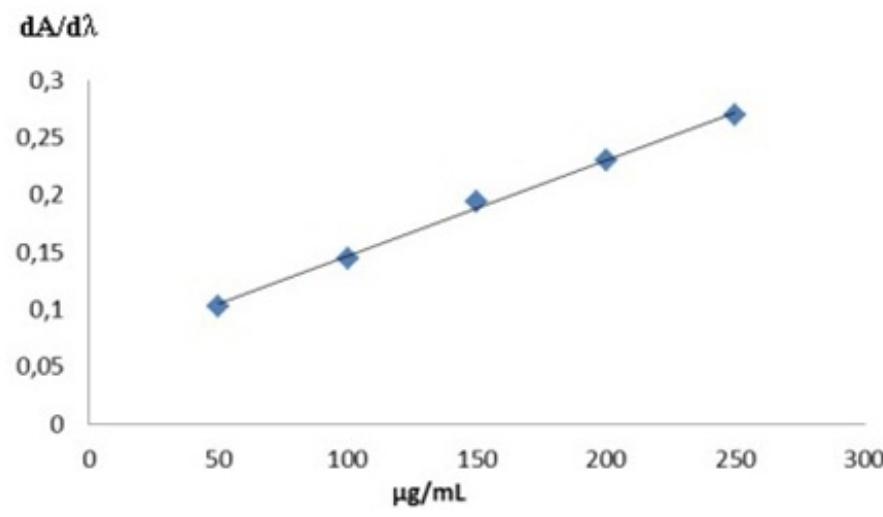

Figure 4. Calibration curve of RIL for first order derivative spectrophotometric method.

Table 1. Optical characteristics and statistical data for zero order derivative spectrophotometric method.

\begin{tabular}{ll}
\hline Parameters & Value \\
\hline Linearity $(\mu \mathrm{g} / \mathrm{mL})$ & $50-250$ \\
Regression equation & $\mathrm{y}=0.0024 \mathrm{x}+0.2362$ \\
Slope & 0.0024 \\
Intercept & 0.2362 \\
Correlation coefficient & 0.9997 \\
LOD $(\mu \mathrm{g} / \mathrm{mL})$ & 0.97 \\
LOQ $(\mu \mathrm{g} / \mathrm{mL})$ & 2.9 \\
\hline
\end{tabular}


Table 2. Optical characteristics and statistical data for first order derivative spectrophotometric method.

\begin{tabular}{ll}
\hline Parameters & Value \\
\hline Linearity $(\mu \mathrm{g} / \mathrm{mL})$ & $50-250$ \\
Regression equation & $\mathrm{y}=0.0008 \mathrm{x}+0.0627$ \\
Slope & 0.0008 \\
Intercept & 0.0627 \\
Correlation coefficient & 0.9977 \\
LOD $(\mu \mathrm{g} / \mathrm{mL})$ & 0.78 \\
LOQ $(\mu \mathrm{g} / \mathrm{mL})$ & 2.7 \\
\hline
\end{tabular}

\subsubsection{Limit of detection and limit of quantification}

Linearity range, regression eq. , correlation coefficient, LOD and LOQ $(n=3)$ from the eq. of (standard deviation of intercept)/(slope of regression eq.) by multiplying 3.3 and 10, respectively. LOD and LOQ values were calculated as 0.97 and $2.9 \mu \mathrm{g} / \mathrm{mL}$, respectively for zero order spectrophotometric method and 0.78 and $2.7 \mu \mathrm{g} / \mathrm{mL}$, respectively for first order derivative spectrophotometric method. [26]

\subsubsection{Precision and accuracy}

$250 \mu \mathrm{g} / \mathrm{mL}$ of RIL were analyzed in six independent series in the same day (intra-day precision) and 3 consecutive days (inter-day precision). The accuracy and precision of the method was expressed by relative mean error (RME \%) and by relative standard deviation (RSD \%), respectively. Intra- and inter-day precision and accuracy were calculated by measuring according to first order derivative spectrum of RIL was measured. The intra-day accuracy ranged from $0.1 \%$ and the inter-day accuracy ranged from $0.12 \%$. The intra-day precision ranged from 0.38 , and the inter-day precision ranged from $0.21 \%$.

\subsubsection{Recovery}

The recovery studies were performed by adding known amounts of the compounds studied to a known concentration of the commercial pharmaceutical tablets (standard addition method). The \% recovery of the added pure drug were calculated as

$$
\% \text { Recovery }=[(\mathrm{Cv}-\mathrm{Cu}) / \mathrm{Ca}] \times 100
$$

where $\mathrm{Cv}$ is the total tag concentration Measured after standard addition; $\mathrm{Cu}$ drug concentration in the formulation; $\mathrm{Ca}$, drug concentration added to formulation. The recovery were found to be $99.54 \% \pm 0.47$ and $99.33 \% \pm 0,21$ for zero and first order derivative spectrophotometric method, respectively.

\subsection{Forced degradation studies}

RIL exhibited extensive degradation under acidic $(0.1 \mathrm{M} \mathrm{HCl})$ condition, as about 28.83 and $28.97 \%$ degradation occurred after $8 \mathrm{~h}$ by zero and first order derivative spectrophotometric method, respectively (Table 3-4). The drug was degraded in acidic conditions; however, the absorbance (height) of the RIL peak decreased. First order derivative spectrum of acidic degraded RIL was shown in Figure 5. The drug was relatively degraded under basic and oxidative conditions $\left(0.1 \mathrm{M} \mathrm{NaOH}\right.$ and $3 \% \mathrm{v} / \mathrm{v} \mathrm{H}_{2} \mathrm{O}_{2}$ solutions). It was observed that there was $100 \%$ degradation after $0 \mathrm{~h}$ by both of spectrophotometric methods. The drug was comparatively stable to acid hydrolysis more than basic and oxidative degradation. There was severe decomposition of the drug on basic and oxidative degradation. As first order derivative spectrophotometric method is more sensitive, asidic degradation results analysed by using first order derivative spectrophotometric method are higher than zero order derivative spectrophotometric method, relatively. 


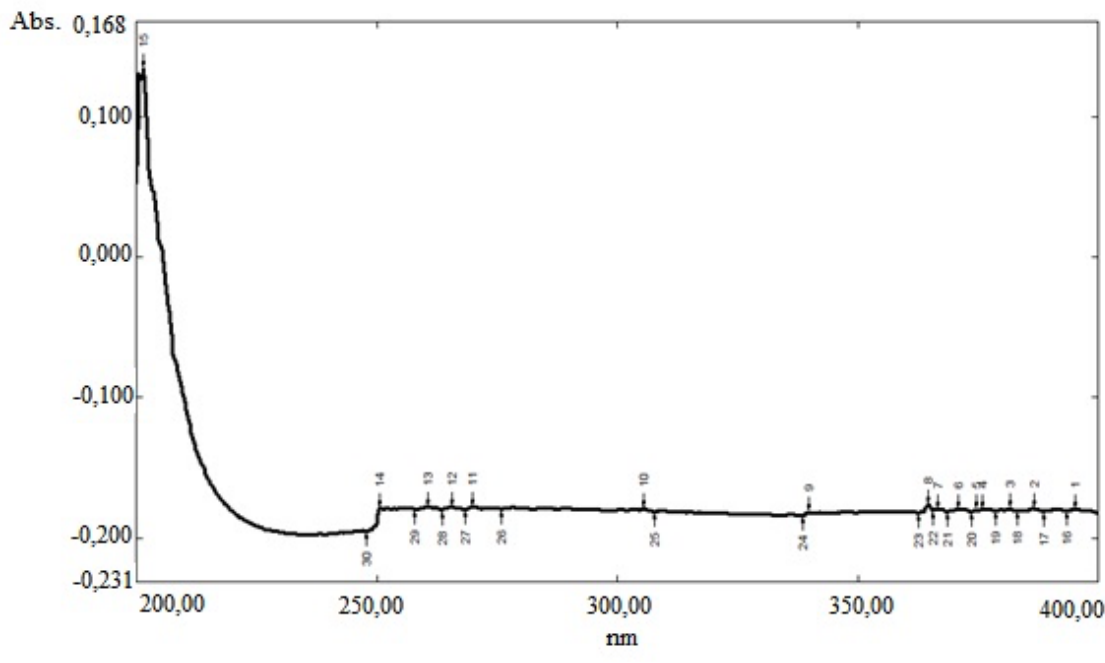

Figure 5. First order derivative spectrum of acidic degraded RIL.

Table 3. Percent of decomposed of degraded RIL by zero order derivative spectrophotometric method according to peak to peak amplitudes.

\begin{tabular}{lllll}
\hline Time & Acidic degradation, A & $\%$ & Basic and Oxidative Degradation, A & $\%$ \\
\hline $0 \mathrm{~h}$ & 0.562 & 0 & Decomposed & 100 \\
$1 \mathrm{~h}$ & 0.525 & 6.59 & & \\
$2 \mathrm{~h}$ & 0.473 & 15.84 & & \\
$4 \mathrm{~h}$ & 0.469 & 16.55 & & \\
$6 \mathrm{~h}$ & 0.469 & 16.55 & & \\
$8 \mathrm{~h}$ & 0.400 & 28.83 & & \\
\hline
\end{tabular}

Table 4. Percent of decomposed of degraded RIL by first order derivative spectrophotometric method according to peak to peak amplitudes.

\begin{tabular}{lllll}
\hline Time & Acidic degradation, A & $\%$ & Basic and Oxidative Degradation, A & $\%$ \\
\hline $0 \mathrm{~h}$ & 0.145 & 0 & Decomposed & 100 \\
$1 \mathrm{~h}$ & 0.135 & 6.9 & & \\
$2 \mathrm{~h}$ & 0.130 & 10.34 & & \\
$4 \mathrm{~h}$ & 0.121 & 16.55 & & \\
$6 \mathrm{~h}$ & 0.121 & 16.55 & & \\
$8 \mathrm{~h}$ & 0.103 & 28.97 & & \\
\hline
\end{tabular}

\section{CONCLUSIONS}

There is no publication concerning the UV spectrophotometric determinations of RIL as finished product in the current literature.In this study, RIL has been determined to determine using zero and first order derivative spectrophotometric methods. In addition, we worked forced degradation study of RIL for the first time. Proposed methods were sensitive, rapid, accurate, and reliable for the determination of RIL in pure and tablets. The method developed can well be proposed for both routine pharmaceutical analyses.

\section{MATERIAL AND METHODS}

\subsection{Reagents and chemicals}

All chemicals and reagents used were of analytical grade. RIL was kindly provided by Servier (Istanbul, Turkey). Hyperium ${ }^{\circledR}$ tablets $(1 \mathrm{mg})$ (Servier, İstanbul, TR) was purchased from a local pharmacy.

\subsection{Preparation of standard and working stock solution}

Stock solution was prepared in water at a concentration of $5 \mathrm{mg} / \mathrm{mL}$ RIL.Working solution is prepared at a concentration of $500 \mu \mathrm{g} / \mathrm{mL}$ RIL by diluting the stock solution with distilled water. 


\subsection{Optimization}

Liquid-liquid extraction experiments were carried out in basic medium to convert the phosphate salt of rilmenidine to base and extract into an organic solvent. For this purpose $0.1 \mathrm{M} \mathrm{NaOH}, 0.1 \mathrm{M} \mathrm{NH}_{4} \mathrm{OH}$ and dichloromethane, chloroform, ethylacetate solvents were used. In order to determine the optimal condition, spectra of this rilmenidine were taken at the maximum absorbance wavelength that these solutions showed. The highest absorbance value was obtained by extraction with dichloromethane of rilmenidine, which was converted to its base with $0.1 \mathrm{M} \mathrm{NaOH}$ solution

\subsection{Methods}

\subsubsection{Zero and first order derivative spectrophotometric method}

Aliquots of RIL working solution were added, so that the final concentration was in the range 50-250 $\mu \mathrm{g} / \mathrm{mL} .1 \mathrm{~mL}$ of $0.1 \mathrm{M} \mathrm{NaOH}$ was added. The solution was mixed vigorously. The content of the tube was extracted three times with $1.5 \mathrm{~mL}$ of dichloromethane.For zero order derivative spectrophotometric method, absorbances of RIL were measured at $224 \mathrm{~nm}$ and the distances between two extremum values (peak-to-peak amplitudes), $223.20-230.20 \mathrm{~nm}(\Delta \lambda=2 \mathrm{~nm})$, were measured in the first derivative $(\mathrm{dA} / \mathrm{d} \lambda)$ spectra of standard solutions of the concentration ranges of $250-500 \mu \mathrm{g} / \mathrm{mL}$. The calibration curves were plotted both of spectrophotometric methods.We calculated the amount \% of degraded in all degradation studies to provide an indication of the stability-indicating property and specificity of the proposed methods.

\subsubsection{Acidic and basic degradation}

$50.0 \mathrm{mg}$ of RIL was waited in $5 \mathrm{~mL}$ of $0.1 \mathrm{M} \mathrm{HCl}$ (acidic degradation) and $5 \mathrm{~mL}$ of $0.1 \mathrm{M} \mathrm{NaOH}$ (basic degradation) at room temperature for 8 hours. The first order derivative spectrum of the RIL was measured in between two extremum values (peak-to-peak amplitudes), $223.20-230.20 \mathrm{~nm}(\Delta \lambda==2 \mathrm{~nm})$ for first order derivative spectrophotometric method and the absorbances of RIL were measured at $224 \mathrm{~nm}$ for zero order derivative spectrophotometric method. We calculated $\%$ of the amount of degraded.

\subsubsection{Oxidative degradation}

To study hydrogen peroxide-induced degradation, initial studies were performed in $3 \%$ hydrogen peroxide at room temperature immediately for all spectrophotometric methods.

\subsection{Procedure for tablets}

Ten tablets of RIL were accurately weighed. A portion of the powder equivalent to $50.0 \mathrm{mg}$ RIL was transferred into a $100 \mathrm{~mL}$ calibrated flask and dissolved in $50 \mathrm{~mL}$ of dichloromethane. The contents of the flask were sonicated for 30 minutes and then completed to volume dichloromethane. This solutions were prepared three times and the absorbance of each solution were determined at $224 \mathrm{~nm}$ and $223.20-230.20 \mathrm{~nm}(\Delta \lambda==2 \mathrm{~nm})$ with all spectrophotometric methods. All determinations were conducted in triplicate.

\subsection{Method validation}

Method validation was performed by following the International Conference on Harmonization ICH guidelines for analytical method validation [26].

Acknowledgements: This work was supported by the Research Fund of the University of Namik Kemal (Project no: NKUBAP.00.GA.16.026).

Author contributions: Concept - A.K. ; Design - A.K., E.O.; Supervision - A.K.; Resource - This work was supported by the Research Fund of the University of Namik Kemal; Materials - This work was supported by the Research Fund of the University of Namik Kemal; Data Collection \&/or Processing - E.O.; Analysis \&/or Interpretation - E.Ö.; Literature Search - A.K.; Writing - A.K.; Critical Reviews - A.K., E.O.

Conflict of interest statement: The authors declared no conflict of interest

\section{REFERENCES}

[1] Head GA, Chatzivlastou K, Lukoshkova EV, Jennings GL, Reid CM. A novel measure of the power of the morning blood pressure surge from ambulatory blood pressure recordings. Am J Hypertens. 2010; 23(10): 1074-1081. [CrossRef] 
[2] Head GA, Reid CM, Shiel LM, Jennings GL, Lukoshkova EV. Rate of morning rise in blood pressure is elevated in hypertensives. Am J Hypertens. 2006; 19(10): 1010-1017. [CrossRef]

[3] Kario K, Ishikawa J, Pickering TG, Hoshide S, Eguchi K, Morinari M, et al. Morning hypertension: the strongest independent risk factor for stroke in elderly hypertensive patients. Hypertens Res. 2006; 29 (8): 581-587. [CrossRef]

[4] Kearney PM, Whelton M, Reynolds K, Muntner P, Whelton PK, He J. Global burden of hypertension: analysis of worldwide data. Lancet. 2005; 365 (9455): 217-223.

[5] Writing Group Members, Mozaffarian D, Benjamin Ej, et al. Executive summary: heart disease and stroke statistics2016 update: A report from the American heart association. Circulation. 2016; 133(4): 447-454. [CrossRef]

[6] Kearney PM, Whelton M, Reynolds K, Whelton PK, He J. Worldwide pre-valence of hypertension: a systematic review. J Hypertens. 2004; 22: 11-19.

[7] Cappuccio FP, Miller MA. Cardiovascular disease and hypertension in sub- Saharan Africa: burden, risk and interventions. Intern Emerg Med. 2016; 11: 299-305. [CrossRef]

[8] Mohammed NM, Sher Abdo HR, Hassan HM. Method development and valıdation of simultaneous determination of hydrochlorothiazıde and losartan in tablet dosage form by RP-HPLC. Int J Pharm Sci \& Res. 2019; 10(1): $227-231$. [CrossRef]

[9] Mahrouse MA. Simultaneous ultraperformance liquid chromatography/tandem mass spectrometry determination of four antihypertensive drugs in human plasma using hydrophilic-lipophilic balanced reversed-phase sorbents sample preparation protocol. Biomed Chromatogr. 2018; 32(12): e4362. [CrossRef]

[10] Magdy R, El-Khatib AH, Hemdan A, Elaziz QA, Farouk M, Linscheid MW. Comparative pharmacokinetics of trandolapril, its active metabolite, and verapamil in human plasma of Egyptian population using HPLC-MS/MS. Drug Test Anal. 2018; 10(7): 1158-1167. [CrossRef]

[11] Babarahimi V, Talebpour Z, Haghighi F, Adib N, Vahidi H.Validated determination of losartan and valsartan in human plasma by stir bar sorptive extraction based on acrylate monolithic polymer, liquid chromatographic analysis and experimental design methodology. J Pharm Biomed Anal. 2018; 153: 204-213. [CrossRef]

[12] Santala EE, Rannikko A, Murtola TJ.Antihypertensive drugs and prostate cancer survival after radical prostatectomy in Finland-A nationwide cohort study. Int J Cancer. 2019; 144(3): 440-447. [CrossRef]

[13] Reid JL. Rilmenidine: a clinical overview. Am J Hypertens. 2000; 13(6 Pt 2): 106S-111S. [CrossRef]

[14] PubChem, Open Chemistry Database. http://pubchem.ncbi.nlm.nih.gov (Accessed: January 4, 2019).

[15] Sweetman SC (ed.). Martindale: The Extra Pharmacopoeia, pp. 996, 34th edition. London: The Pharmaceutical Press; 2005.

[16] Servier. Summary of product characteristics: Hyperium. http://www.servier.com. (Accessed:January 31, 2019).

[17] Chytil L, Cvačka J, Marešová V, Štrauch B, Widimský J, Štícha JM, Slanař O. Development of a fast LC-MS/MS method for quantification of rilmenidine in human serum: elucidation of fragmentation pathways by HRMS. J Mass Spec. 2010; 45: 1179-1185. [CrossRef]

[18] Ambadas RR, Swapnil RB. First-order derivative spectrophotometric estimation of nabumetone and paracetamol in tablet dosage form. Pharm Methods. 2011; 2(4): 260-263. [CrossRef]

[19] Ojeda CB, Rojas FS. Recent developments in derivative ultraviolet/visible absorption spectrophotometry. Anal Chim Acta. 2004; 518: 1-24. [CrossRef]

[20] International Conference on Harmonization, Stability Testing of New Drug Substances and Products, in: International Conference on Harmonization, 1993.

[21] Rojas FS, Ojeda CB, Pavon JM. Derivative ultraviolet - visible region absorption spectrophotometry and its analytical applications. Talanta. 1988; 35: 753-761. [CrossRef]

[22] Karpińska J. Derivative spectrophotometry - recent applications and directions of developments. Talanta. 2004; 64: 801-822. [CrossRef]

[23] Shirkhedkar AA, Bhirud HC, Surana JS. Application of UV-spectrophotometric methods for estimation of tenofovir disoproxil fumarate in tablets. Pak J Pharm Sci. 2009; 22: 27-29.

[24] Jenee C, Purvi S, Margi P, Kalpana P, Tejal G. Optimizing derivatization conditions using an experimental design and simultaneous estimation of artemether and lumefantrine by ratio first order derivative spectrophotometric method. J Taibah Univ Sci. 2017; 11: 729-740. [CrossRef] 
[25] Dimal AS, Dixita JS, Chirag ND, Usman KC, Kashyap KB, Estimation of ibuprofen and famotidine in tablets by second order derivative spectrophotometry method. Arab J Chem. 2017; 10: 105-108. [CrossRef]

[26] International Conference on Harmonization. ICH. Validation of analytical procedures: text and methodology Q2 R1. 2005.

[27] International Conference on Harmonization, ICH. Stability testing of new drug substances and products Q1A R2 2003.

This is an open access article which is publicly available on our journal's website under Institutional Repository at http://dspace.marmara.edu.tr. 